FERMILAB-TM-1950

\title{
Recycler Model Magnet Test on Temperature Compensation for Strontium Ferrite
}

\author{
R. Yamada, W. Foster and F. Ostiguy \\ Fermi National Accelerator Laboratory \\ P.O. Box 500, Batavia, Illinois 60510
}

\author{
M. Wake \\ KEK \\ Japan
}

October 1995 


\section{Disclaimer}

This report was prepared as an account of work sponsored by an agency of the United States Government. Neither the United States Government nor any agency thereof, nor any of their employees, makes any warranty, expressed or implied, or assumes any legal liability or responsibility for the accuracy, completeness, or usefulness of any information, apparatus, product, or process disclosed, or represents that its use would not infringe privately owned rights. Reference herein to any specific commercial product, process, or service by trade name, trademark, manufacturer, or otherwise, does not necessarily constitute or imply its endorsement, recommendation, or favoring by the United States Government or any agency thereof. The views and opinions of authors expressed herein do not necessarily state or reflect those of the United States Government or any agency thereof. 


\section{Recycler Model Magnet Test \\ on Temperature Compensation for Strontium Ferrite}

October 11, 1995

R. Yamada, W. Foster, and F. Ostiguy, Fermilab

and

M. Wake, KEK, Japan

The Recycler ring magnet will be made of Strontium ferrite permanent magnets (1). A strontium ferrite permanent magnet without compensation has a temperature coefficient of $-0.2 \%$ in $\mathrm{dB} / \mathrm{dT}$. To compensate this effect, we are utilizing $30 \% \mathrm{Ni} 70 \% \mathrm{Fe}$ alloy, a temperature compensation ferromagnetic material with a low Curie point.

To search for optimum commercially available material and optimum condition, we made a couple of simple model magnets, and tested with several different compensating material. The test results are reported and its optimal conditions are shown. Several different configurations were tested including a possible $2 \mathrm{kG}$ magnet configuration.

\section{Geometry of Model Test Magnets.}

In order to test the effect of temperature compensation with different material in short time and with minimally available material, we made short magnets; one 1 foot magnet and another 2 foot magnet. We made these magnets utilizing mirror plates, and the cross section of the last model magnet is shown in Fig. 1. The top ferrite magnet bricks, 1 " thick, 6" wide and 4" long are placed between the pole piece and the top yoke plate. The side ferrite magnets, 1 " thick, 2" wide and 6" long, are placed on both sides of the pole piece, butting to its side surfaces.

For simplicity of testing we used one inch thick flat pole pieces, instead of gradiented pole pieces. The pole pieces are held tight to the mirror plate with one inch high aluminum spacers at both edges of the gap, keeping a constant gap dimension. The pole piece is made 6.020" wide, because the available one inch thick Sr. ferrite bricks of 6" by 4", had a bigger width than 6.0". The thickness of the Sr. ferrite bricks is made 1.000" +- 0.005". The compensators are made of 6" x 1" strips, 40 or 50 mils thick, and are made narrower than ferrite bricks. 
In this series tests, packages of the compensator about 9 to 25 pieces together, and ferrite bricks are placed alternately along the length of the magnet. In a typical case for the 2 foot magnet, we placed the compensator packages of 9 pieces at both ends and the packages of 19 pieces between the adjacent top ferrite bricks, which is designated by 9-19-19-19-19-9. or simply designated by " -19 ". We installed all necessary compensators between the top 4 x 6 bricks, not any between side bricks.

The lengths of the pole pieces are $25 "$ and $12 "$ for the 2 ' magnet and 1' magnet respectively. For each configuration, we added additional pole pieces with 1 inch increment as needed. We made the length of the pole piece as close as to the total assembled length of ferrite bricks and compensators.

\section{Strontium Permanent Ferrite Bricks}

The available top bricks have dimensions of 4" x 6" x 1". Only the 1" thickness was controlled to $1.000 "+-0.005 "$. The other dimensions are loose, but from the stand point of assembly, they should be specified and controlled. The side bricks 2 "(=1.95") x 6 " x 1 " were made by cutting 4" x 6" x 1" bricks into two halves. We used AA company ferrite bricks for the test of the 2' magnet, just because of their availability. For the 1' magnet we used AA company bricks in some cases and BB and CC type 8 bricks in others.

The side bricks help to increase the magnetic flux density in the magnet gap, by adding their magnetizing force and also preventing the magnetic flux from leaking into the side yokes. Their vertical position relative to the pole pieces is not optimized in this series test, but seems close to its optimum position.

\section{Magnetic Field Distribution in Gap at Room Temperature}

The magnet has a cross section as shown in Fig. 1. We used 5 AA company top 6 x 4 bricks and 8 AA company 2 x 6 side bricks and DD company compensators with the configuration of 9-19-19-19-19-9. The package of 19 pieces is 1.0 " thick and the 9 piece package is 0.5 " wide. The length of the pole piece is $25 "$, and the total length of the top bricks and the compensator packages is also $25 "$. The length of the yoke is $29 "$, extending $2 "$ on both sides of the pole piece.

The magnetic field distributions in the gap of the 2 foot magnet are shown in Fig. 2 and 3. The vertical field component $\mathrm{By}(\mathrm{z})$ on the $\mathrm{z}$-axis is measured at 1 " interval, and the data is shown in Fig. 2. It is quite uniform, but show a tendency of slight dips at places where the compensators are placed. The effective magnetic length is about 26.5", which is longer than that of the pole pieces by 
1.5". The surfaces of the mirror plate and aluminum spacers were not machined, causing some irregularities in the field distribution.

The vertical field distribution $\mathrm{By}(\mathrm{x})$ across the gap at the center of the magnet is shown in Fig. 3. The field distribution is not uniform because of the geometrical factors. There is a quadrupole term due to the non-uniformity of the gap, and the positioning errors in the side bricks. For further tests, we should correct these factors to a minimum.

\section{Temperature Compensator}

The required characteristics of the temperature compensators are as follows,

1. The temperature derivative of the magnetic flux, $\mathrm{dB} / \mathrm{dT}$, should be large. Possibly over 50 Gauss/degree C.

2. For the Recycler magnet with operation temperature at 25 degree $\mathrm{C}$, the derivative should be linear over the range from 20 degree $\mathrm{C}$ (=68 degree $\mathrm{F})$ to 30 degree $\mathrm{C}$ (=86 degree $\mathrm{F})$.

For the $9 \mathrm{GeV}$ beam line application with a lower operation temperature at 18 degree $\mathrm{C}(=64.4$ degree $\mathrm{F})$, the temperature range is from 10 degree $\mathrm{C}(=50 \mathrm{~F}$ degree) to 25 degree $\mathrm{C}(=74$ degree $\mathrm{F})$.

3. The magnetic flux density B inside the compensator should not be excessively high at its operation temperature. Otherwise the compensator extracts too much magnetic flux from the permanent magnet, resulting the reduction of the magnetic flux density value B in the gap.

We tested samples of the temperature compensators, from DD Co., EE Co., and FF Co. We made samples 6" by $1 "$ (=0.990"+- $0.005 ")$. The thickness are 50 mils or $1 \mathrm{~mm}$ (=40 mils) for the material.

Their magnetic characteristics are listed in Table I, which are derived from the company's specifications usually at lower magnetic field.

\section{Test Procedure}

Assembled 2 foot magnet is directly wrapped with 4 heating tapes, each $125 \mathrm{~W}$. Then the whole assembly is covered up with a glass wool blanket, and a sheet of thick aluminum foil. The 1 
foot magnet is heated with 3 heating tapes and covered with a sheet of glass fiber insulation sheet. The magnet is heated up from room temperature ( 22 degree $\mathrm{C}$ ) to 40 degree $\mathrm{C}$ in about 70 minutes, and the heater is turned off. The magnet is cooled down in about one day, with a time constant of roughly 6 hours.

During this thermal cycle, the magnetic field, $\mathrm{By}(0)$, and the temperature, $\mathrm{T}$, at the center of the magnet in the gap are recorded using MDTF data acquisition system. The magnetic field strength at a quarter inch away from the mirror surface, is measured with a Group 3 Hall Gaussmeter, which is temperature compensated, and the temperature is measured with a platinum thermo-couple, which was calibrated by MDTF group.

\section{Typical Test Data for Temperature Compensation}

The variation of magnetic field $\mathrm{By}(0)$, due to the temperature is shown in Fig. 4. The curve in the Fig. 4, is composed of two parts, one corresponding to the heating-up period and the cooling-down period, as is indicated by the time arrows.

During the heating period, the magnet yoke is heated up locally by the heating tapes, and the temperature distribution inside the magnet become non-uniform. The temperature distributions in the top bricks, in the side bricks, in the compensators, as well as in the probe area, are quite different. Therefore, the curve corresponding to the heating period should not be used. About 30 minutes after the heater is turned off, we can assume the thermal equilibrium is established. During the cooling period, the magnet is thermally isolated, and the temperature distribution in the whole magnet can be assumed uniform. The thermal decay time constant of the 2 foot magnet system is about 6 hours and cool down to the room temperature is over a day. The data corresponding to the long cooling period is the valid data, which we should use. With this magnet configuration, the thermal cycling was done twice and we got reproducible data.

We still have to make sure that there is no noticeable effect due to the hysteresis of the strontium ferrite or of the ferromagnetic compensator. And to do a more perfect study, we should use a constant temperature box, the temperature of which can be programmed up and down, at least for a couple of thermal cycles. Its temperature range should cover down from at least 0 degree $\mathrm{C}$ and up to 40 degree $\mathrm{C}$.

There is some theory that there is some hysteresis effect for the first big thermal cycling, and then there is no hysteresis effect for the subsequent thermal cycling with less thermal range. If this is true, we must have to do thermal cycling of every newly produced magnet for a wide temperature range before production test of the magnet. After production and testing of each magnet, the magnet 
will be subjected to some extensive thermal cycling during its transit and installation in the tunnel. We should avoid exposing the tested magnet in transit to an extreme outside temperature during winter.

\section{Testing with Compensator Removed}

In order to calculate the magnetic flux density in the compensator, we tested the same 2 foot magnet with the same configuration but without the compensators. The central field went up to 1642.2 Gauss at 21.2 degree $C$ from 1461.80 Gauss at 21.8 degree $C$ with compensators in place. It is $12.3 \%$ increase in the central field.

With this configuration, the magnetic field vector inside the volume, where the compensators are placed, was measured experimentally by exposing the hole by partially sliding the side yoke plate and by removing a side brick. It was about -1532 Gauss inside the hole, while the magnetic flux in the magnetic gap just above that place was, +1473 Gauss. The magnetic field in the gap at the other side of the non-disturbed part had + 1630 Gauss. In the non-disturbed area, we can expect the field strength of $-1532 \times 1630 / 1473=-1695$ Gauss inside the volume, where the compensator is placed.

\section{Testing with all Space Filled up with Ferrite}

For a further study we filled the top ferrite space, with six 4" x 6" AA Co. bricks, with the total length of $24 "$, while keeping the 25 " length of the pole piece. Then the central field went up further to 1808.8 Gauss. This is $23.7 \%$ increase over the compensated field value of 1461.80 Gauss. This value is well over 1700 Gauss needed for the design of the $8 \mathrm{GeV}$ line magnet.

\section{Comparison of Test Data with Different Compensation Material}

The important parameters for the test results are,

1. Magnetic field deviation $(\mathrm{B}(\mathrm{T})$ - $\mathrm{B}(\mathrm{T} 0)) / \mathrm{B}(\mathrm{T} 0)$ and $\mathrm{dB} / \mathrm{dT}$

The magnetic field deviation should be smaller $1 \times 10 * *-3$ over the operation temperature range of about 10 degree $\mathrm{C}$. The derivative of magnetic field $\mathrm{dB} / \mathrm{dT}$ should be less than $10 * *-4 /$ degree C. 
2. Central magnetic field $\mathrm{B}(0)$ in gap

The central magnetic field inside the gap is affected and reduced by the compensator. Its reduction value should be minimized by the good choice of the compensator material. It should not be reduced too much. We should choose the compensator material with rather a low Curie point close to the operation point and have a big value of $\mathrm{dB} / \mathrm{dT}$. The value of $\mathrm{dB} / \mathrm{dT}$ should be above 50 Gauss/degree C, possibly 75 .

\section{Volume ratio of Compensator/Ferrite $\mathrm{C} / \mathrm{F}$}

This volume ratio should be smaller, because the bigger the ratio, the less ferrite material is used, resulting a weaker $\mathrm{B}(0)$ value in the gap. Also the total cost of the compensator is increased, which is about 10 times more expensive than ferrite in volume.

The summary of the test data are shown in Table II and III, and in Fig. 5 and 6. In Table II, the configuration of the test setup is listed. In Table III, the important parameters of the test results are shown.

\section{A. Best configuration}

The best condition is achieved with the case 2DD-I9. In this case the central field value $\mathrm{B}(0)$ is 1462 Gauss with $\mathrm{dB} / \mathrm{dT} / \mathrm{B}$ is less than $1 \mathrm{x} 10^{* *}-4$ over the temperature range of 20 to 40 degree $\mathrm{C}$, as is shown in Fig. 6. And the volume ratio $\mathrm{C} / \mathrm{F}$ is about $12.5 \%$. But we still have to test if this is true with different batchs of this product, and how big is the statistical variation.

\section{B. Comparison between 1' magnet and 2' magnet}

The setup for 2DD-18 and 1DD-18 are similar configuration and made of same material, except the length of magnets. The 2' magnet test data 2DD-18 show a higher field value of 1471 Gauss (14\% up), compared to 1286 Gauss of $1 \mathrm{DD}-18$. This difference is due to the $\mathrm{C} / \mathrm{F}$ ratio (8\%), and the fact that the 1' magnet had a bigger gap by about 40 mils (4\%). Losses due to stray flux at the ends of the magnet are estimated to be about $10 \%$ for a 1 ' magnet and $5 \%$ for a 2 ' magnet, resulting in $5 \%$ difference. 


\section{1 ' magnet data}

The 1EE3-30 data show a reasonable $\mathrm{B}(0)$ and magnetic field deviation up to 30 degree $\mathrm{C}$, but with a little more nonlinearity. Also the volume ratio $\mathrm{C} / \mathrm{F}$ is much higher than that of $1 \mathrm{DD}-18$. Both these two cases have similar $\mathrm{B}(0)$ values.

The 1EEl-30 data show that compensation is not enough with this $\mathrm{C} / \mathrm{F}$ ratio and the $\mathrm{B}(0)$ value is low. The case of 1DD-24 is a case with overcompensation.

\section{Fleld deviation}

The curves of the field deviation versus temperature are shown in Fig. 5 and 6 with different vertical scales. The data are normalized at 25 degree C. The data of 2DD19 and 1DD18 designated as "2' DD-19" and "1' DD-18" in the drawing show a quite wide compensate range up to 43 degree $\mathrm{C}$. The data of 2FF-19 designated as "2' FF-19" show a negative slope over a wide temperature range, but could be improved by increasing one more plate $(5 \%)$, with a slight reduction in the central field. The kink at 28 degree $\mathrm{C}$ in " 1 ' DD-24" is due to stat of a rapid cooling with a fan.

\section{Model Magnet Tests with 2 Layer Top Brick.}

We assembled and tested two model magnets incorporating 2 top layers using 1' magnet assembly.

\section{A. 2 layer top and $2 "$ side brick}

The cross section of the magnet is almost same as in Fig. 1, except we added another layer of ferrite and compensator, with both layer composed of 3 AA bricks and 9-19-19-9 DD material. The bottom surfaces of the 2 " side bricks and the pole piece surface are made flush in the gap. The $\mathrm{B}(0)$ value is 1522.5 Gauss, which is $18 \%$ higher than 1 DD-18 case.

\section{B. 2 layer top and 4" side brick: Possible 2 kG magnet}

In this configuration, we used 2 ferrite layers as before, added another 1 " thick identical pole piece, making total 2" thick pole piece, and replaced 2" side bricks by 4" side bricks, utilizing regular 4x6xl bricks. The bottom surfaces of the side bricks are positioned as shown in Fig. 1 relative to the surface of the pole piece. The $\mathrm{B}(0)$ value is 1740.9 Gauss in this setup. If we make a 2 foot model magnet with exact 1" gap as was done before, it is expected the $\mathrm{B}(0)$ value will be raised by 14 $\%$, resulting to 1985 Gauss. 


\section{Comments}

There is quite variations in the specifications of the compensating material. The key element is the specification on "dB/dT - B" curve. The Curie point should not be too high, rather be close to the operation temperature. It may be best 10 to 15 degree $\mathrm{C}$ higher than the upper end point of the operation range. The value of $\mathrm{dB} / \mathrm{dT}$ should be above $50 \mathrm{Gauss} /$ degree $\mathrm{C}$, preferably in the range of 75 Gauss/degree $\mathrm{C}$. The usual industrial acceptance range for $\mathrm{dB} / \mathrm{dT}$ and $\mathrm{B}$ for a specific material is quite wide for our application. These parameters will change drastically with degree of cold rolling and heat treatment, and by a change in chemical composition. A tight control on their quality during mass production will be needed.

\section{Acknowledgments}

We appreciate the various help we received dunng this test from all members of MDTF group. Particularly we thank to the H. Glass, D. Orris and D. Massengill.

\section{Appendix Possibility of Non-temperature Compensated 8 GeV Line Magnet}

As is shown in VIII, we can construct an 1800 Gauss magnet, if we filled up space with ferrite bricks without compensators. In this way we can consider the possibility of building the $8 \mathrm{GeV}$ line magnet without compensators. This type of magnets can be produced more easily and will be less expensive, compared to the fully temperature compensated magnets. The $8 \mathrm{GeV}$ line magnets will be installed in a tunnel where there will be much less temperature variation from other disturbances. The tunnel temperature might be below 20 degree $\mathrm{C}$ all year around. To keep the temperature of magnets constant within +- 0.1 degree, we can use a couple of different ways. In all of the following methods, the magnets will be covered with some thermal insulation.

1. We should be able to provide simple water heating pipes on both sides of the magnet, and make all magnet in the same temperature range.

2. We can provide heating pads for every magnet, and control the temperature of individual magnets by computer monitoring.

3. We can thermally isolate the whole length of the tunnel, and circulate the temperature controlled air using return air pipes.

\section{References}

1) G. Jackson, Editor, "Recycler Ring Conceptual Design Study", FERMILAB-TM-1936, July 18, 1995. 
Table I. Related Magnetic Parameters of Commercial Compensators

These are interpreted from the specifications from the companies.

$\begin{array}{lllllll} & \begin{array}{l}\mathrm{H} \\ \mathrm{Oe}\end{array} & \begin{array}{l}\mathrm{dB} / \mathrm{dT} \\ \mathrm{G} / \mathrm{C}\end{array} & \begin{array}{l}\mathrm{B}(25) \\ \mathrm{G}\end{array} & \begin{array}{l}\text { Range } \\ \mathrm{C}-\mathrm{C}\end{array} & \begin{array}{l}\mathrm{dB} / \mathrm{dT} / \mathrm{B} \\ \% / \mathrm{C}\end{array} & \begin{array}{l}\text { Curie P. } \\ \mathrm{C}\end{array} \\ \mathrm{DD} & 46 & -75 & 1518 & 10-33 & -4.9 & 45 \\ \mathrm{EE}-1 & 100 & -58 & 1950 & 0-40 & & 85 \\ & 400 & -40 & 3600 & 0-40 & & 97 \\ \text { EE-3 } & 50 & -45 & 1200 & 0-25 & & 43 \\ & 400 & -45 & 1770 & 0-30 & & 54\end{array}$

Table II. Test Setup

\begin{tabular}{|c|c|c|c|c|c|}
\hline Case & $\begin{array}{l}\text { Yoke } \\
\text { length }\end{array}$ & $\begin{array}{l}\text { Pole Piece } \\
\text { width length }\end{array}$ & $\begin{array}{l}\text { Top Ferrite } \\
\text { length( } 4 " x 6 ")\end{array}$ & $\begin{array}{l}\text { Side Ferrite } \\
\text { length(6"x2") }\end{array}$ & $\begin{array}{l}\text { Compensator } \\
\text { length }\end{array}$ \\
\hline 2DD-19, & $29 "$ & 6" 25" & $\begin{array}{l}\mathrm{x} 5,=20^{\prime \prime} \\
\mathrm{AA}\end{array}$ & $\begin{array}{l}\mathrm{x} 4,=24 " \\
\mathrm{AA}\end{array}$ & $\begin{array}{l}x 5, x 19, .05 ",=4.7 " \\
9-19-19-19-19-9\end{array}$ \\
\hline 2DD-18, & $"$ & $"$ & $"$ & $"$ & $\begin{array}{l}x 5, x 18, .05 "=4.5 " \\
9-18-18-18-18-9\end{array}$ \\
\hline $2 \mathrm{FF}-19$ & $"$ & $"$ & $"$ & $"$ & $\begin{array}{l}x 5, \text { x19, .05", = 4.7" } \\
\text { 9-19-19-19-19-9 }\end{array}$ \\
\hline 1DD-18, & $16 "$ & 6" 15" & $\begin{array}{l}\mathrm{x} 3,=12^{\prime \prime} \\
\mathrm{CC}\end{array}$ & $\begin{array}{l}\mathrm{x} 2,=12^{\prime \prime} \\
\mathrm{BB}\end{array}$ & $\begin{array}{c}\text { x3, x18, .05", = 2.7" } \\
9-18-18-9\end{array}$ \\
\hline 1DD-24, & $"$ & $16 "$ & $"$ & $"$ & $\begin{array}{c}\text { x3, x } 24, .05 ",=3.6 " \\
12-24-24-12\end{array}$ \\
\hline 1EE3-30 & $"$ & $"$ & $"$ & $"$ & $\begin{array}{c}x 3, x 30,1 \mathrm{~mm},=3.5 " \\
15-30-30-15\end{array}$ \\
\hline 1EE1 -30 & $"$ & $"$ & $"$ & $"$ & $\begin{array}{c}x 3, x 30,1 \mathrm{~mm},=3.5 " \\
15-30-30-15\end{array}$ \\
\hline
\end{tabular}


Table III. Comparison of Test Results

\begin{tabular}{|c|c|c|c|c|c|}
\hline Case & $\begin{array}{l}\text { C/F: Vol. ratio of } \\
\text { compensator/ferrite } \\
(\%)\end{array}$ & $\begin{array}{l}\text { Measu } \\
\mathrm{B}(0) \\
(\mathrm{G})\end{array}$ & $\begin{array}{l}\text { red } \\
\mathrm{T} \\
(\operatorname{deg} \mathrm{C}\end{array}$ & $\mathrm{dB} / \mathrm{dT} / \mathrm{B}$ & $\begin{array}{l}\text { Temp. Range } \\
(\operatorname{deg} C)\end{array}$ \\
\hline 2FF-19 & $\begin{array}{l}4.7 \times 6 / \\
20 \times 6+2 \times 24 \times 2=13.1\end{array}$ & 1,458 & 23.8 & $--2.7 \times 10 * *-4$ & $21.5-40.0(-54.7)$ \\
\hline 2DD-19 & $\begin{array}{l}4.7 \times 6 / \\
20 \times 6+2 \times 24 \times 2=13.1\end{array}$ & 1,462 & 20.6 & $-+5 \times 10 * *-5$ & $20.6-35.0(-44.5)$ \\
\hline 2DD-18 & $\begin{array}{l}4.5 \times 6 / \\
20 \times 6+2 \times 24 \times 2=12.5\end{array}$ & 1,471 & 24.5 & $-+1 \times 10 * *-4$ & $24.5-43.5$ \\
\hline 1DD-18 & $\begin{array}{l}2.7 \times 6 / \\
12 \times 6+2 \times 12 \times 2=13.5\end{array}$ & 1,286 & 22.2 & $-1.2 \times 10 * *-4$ & $22-39$ \\
\hline 1DD-24 & $\begin{array}{l}3.6 \times 6 / \\
12 \times 6+2 \times 12 \times 2=18.0\end{array}$ & 1,176 & 22.2 & $+7.8 \times 10 * *-4$ & $22-44$ \\
\hline 1EE3-30 & $\begin{array}{l}3.5 \times 6 / \\
12 \times 6+2 \times 12 \times 2=17.5\end{array}$ & 1,302 & 23.3 & $\begin{array}{l}-5.1 \times 10 * *-4 \\
(-2 \times 10 * *-4\end{array}$ & $\begin{array}{l}23-41 \\
23-35)\end{array}$ \\
\hline 1EE1-30 & $=17.5$ & 1,248 & 21.8 & $-4.9 \times 10 * *-4$ & $22-40$ \\
\hline$\underset{"}{21 \text { ayer-2"sb }}$ & $\begin{array}{l}2.8 \times 6 \times 2 / \\
12 \times 6 \times 2+2 \times 12 \times 2=17.5\end{array}$ & 1,523 & 22 & & \\
\hline 21ayer-4"sb & $\begin{array}{l}2.8 \times 6 \times 2 / \\
12 \times 6 \times 2+4 \times 12 \times 2=14.0\end{array}$ & 1,741 & 22 & & \\
\hline
\end{tabular}

This type magnet with 2' length with correct 1" gap will reach $2 \mathrm{kG}$. 
Fig 1 Cross Section of Recycler Model Mognets

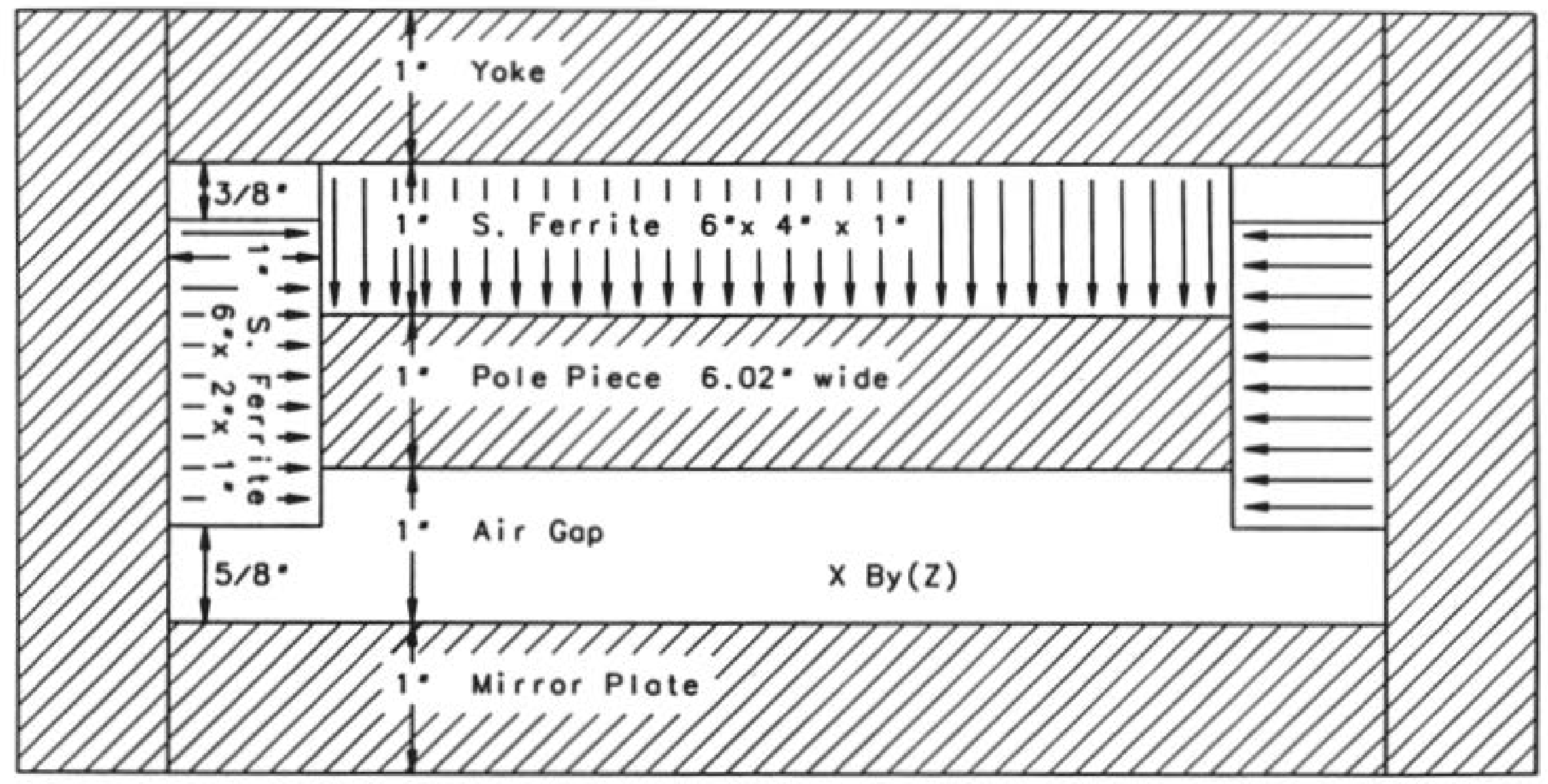


Fig 2 By (Z) Distribution of 2 foot Magnet

B (kG)

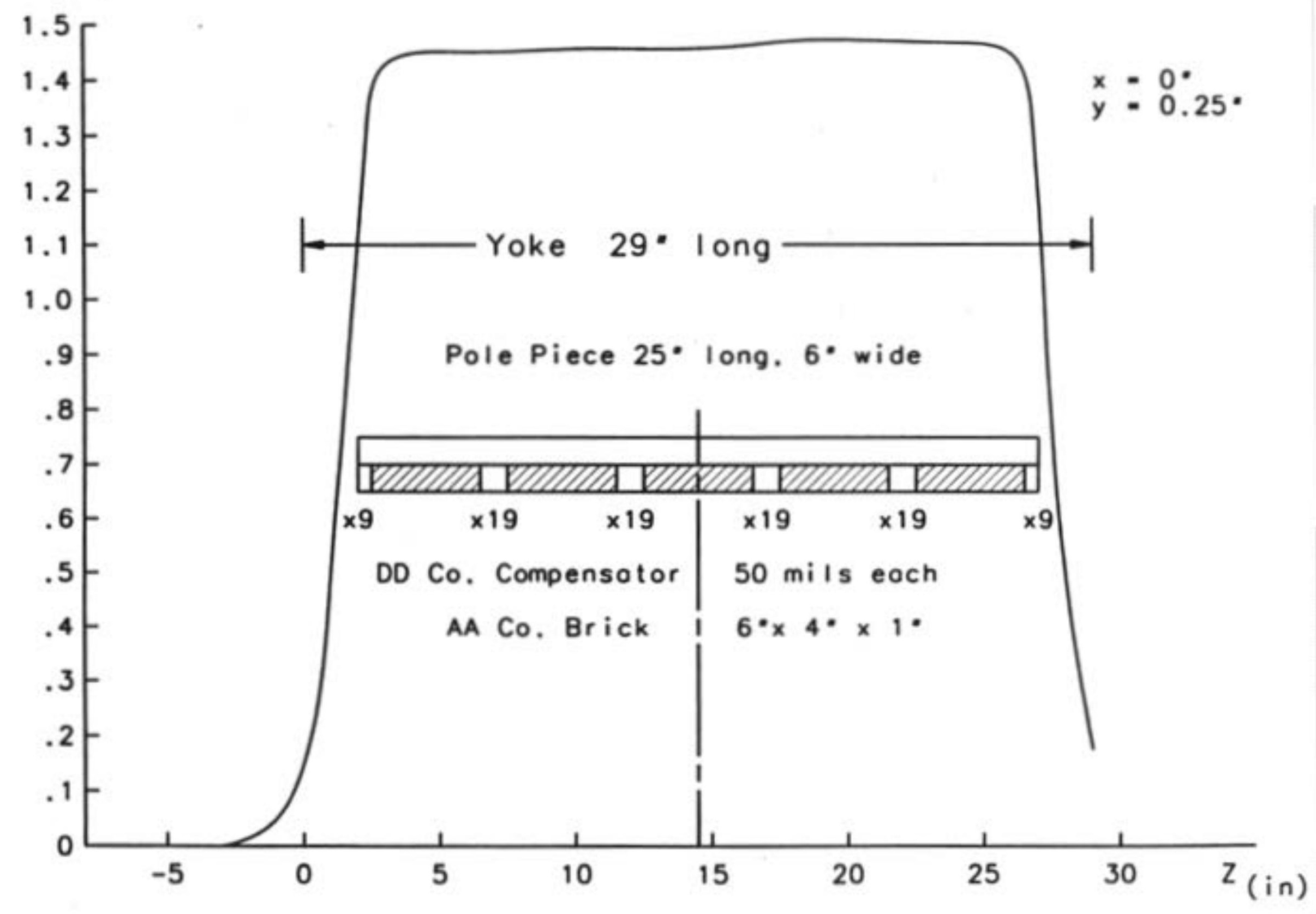




\section{Fig 3 Field Distribution By(X) of 2 foot Magnet}

$\mathrm{By}(\mathrm{X})$

(Gouss)

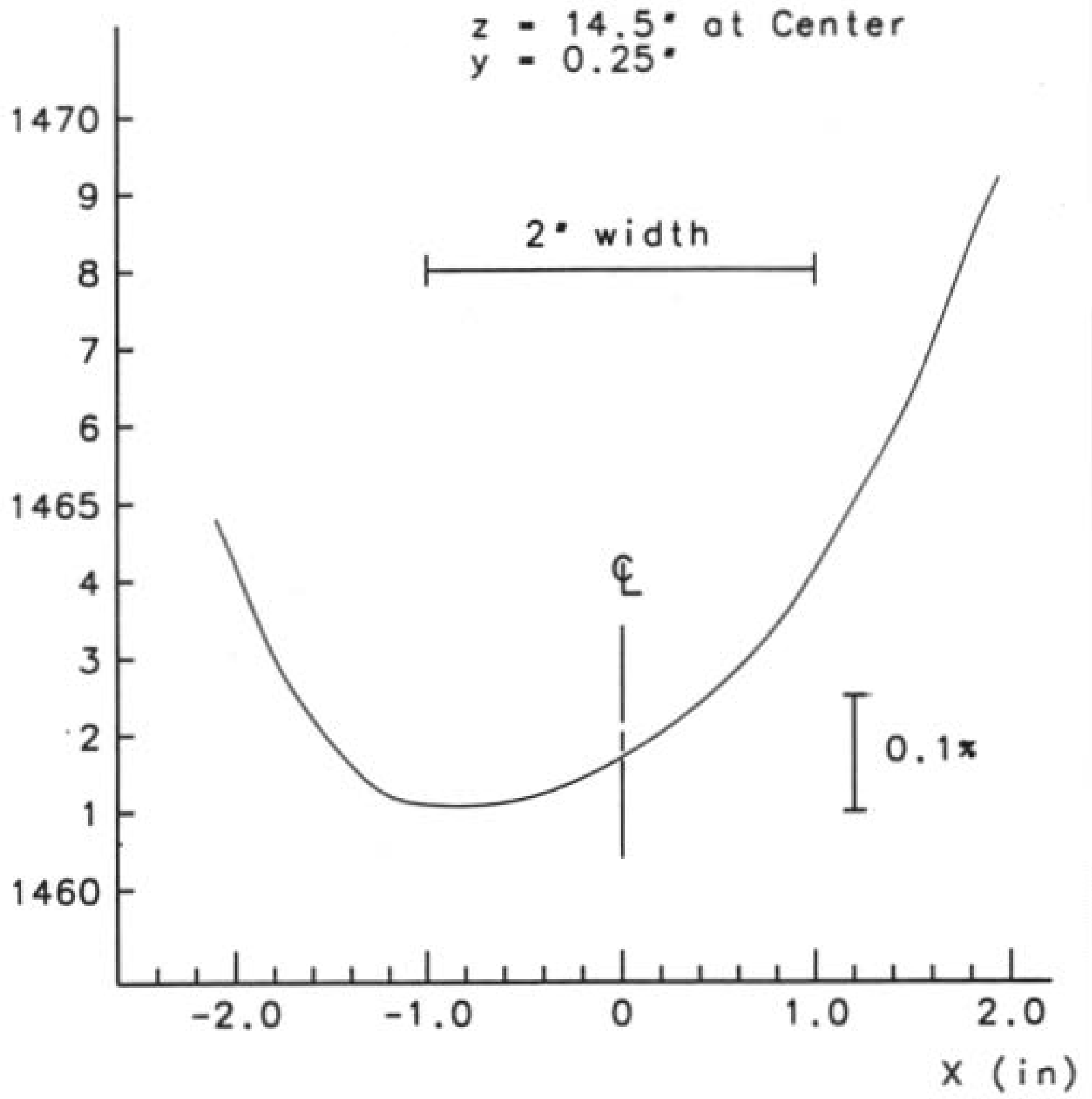


Fig. 4

2' Mag. AA Co. Brick, DD-19 Compensator

9-19-19-19-19-9, 8/18/95 $60 \mathrm{hr}$ run

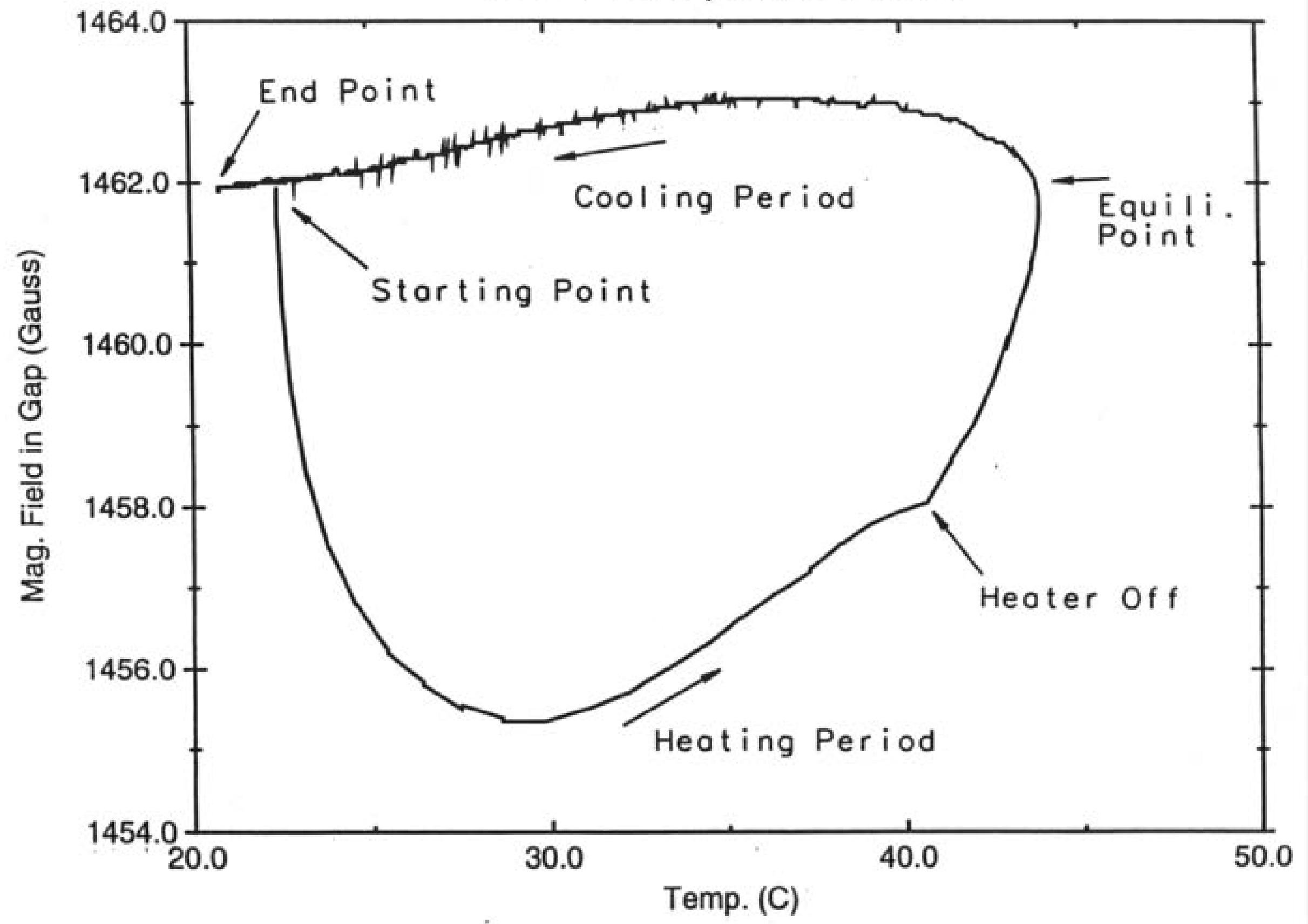




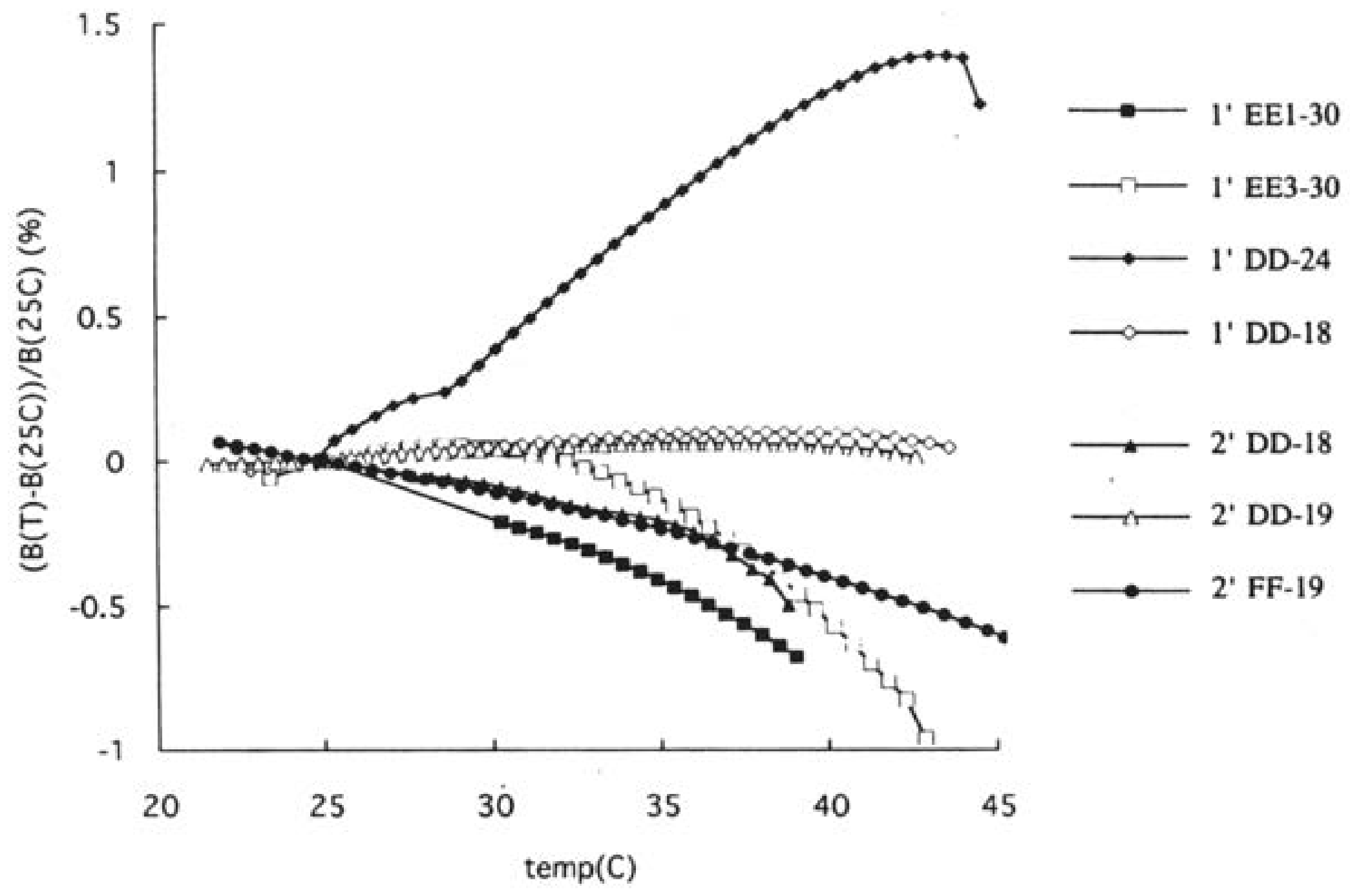

Fig. 5 


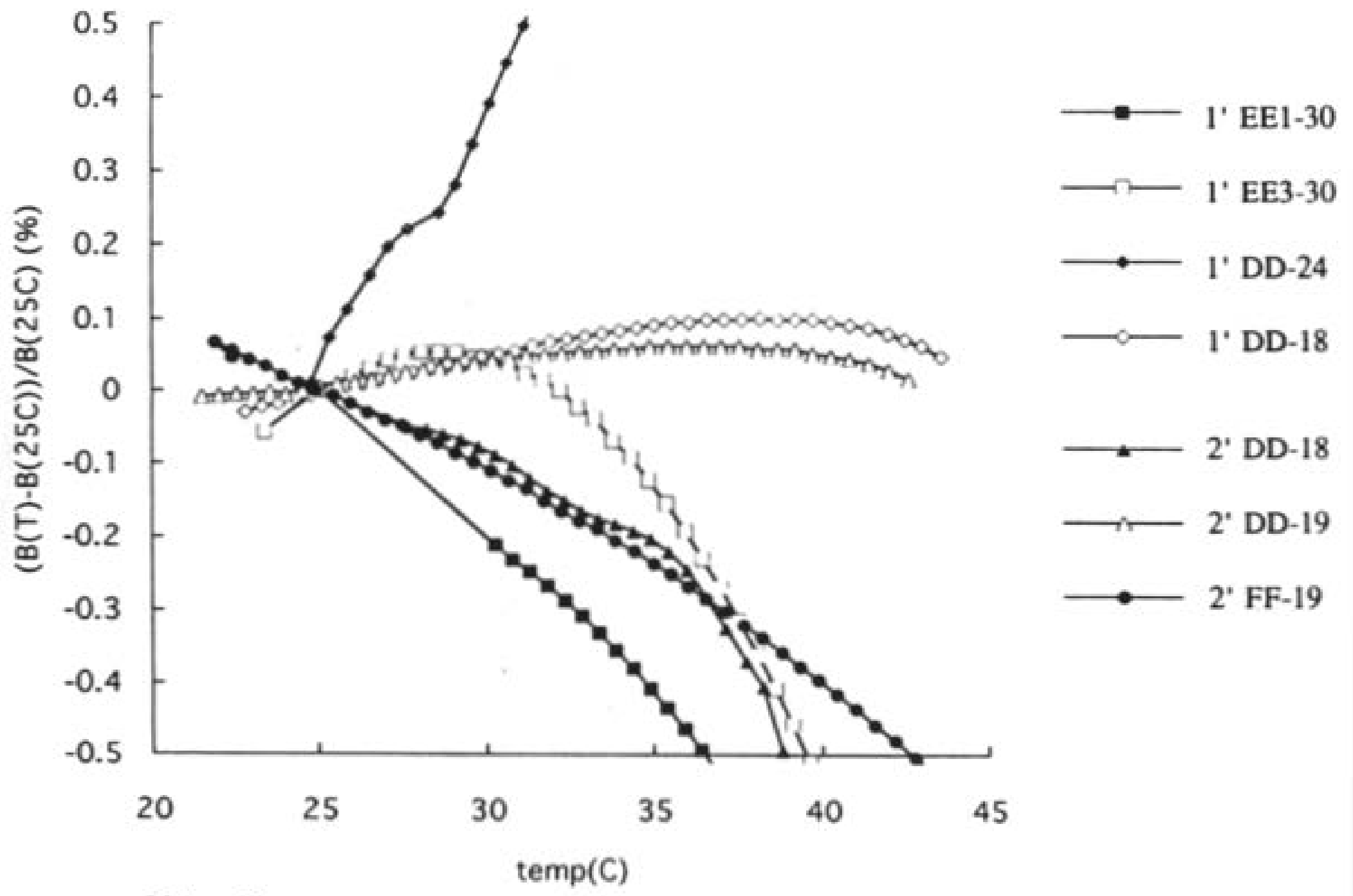

Fig. 6 